\title{
Physicians' prescribing behaviour and clinical practice patterns for allergic rhinitis management in Italy
}

\author{
Giovanni Passalacqua', Antonino Musarra² , Gianenrico Senna ${ }^{3}$, Jean Bousquett ${ }^{4,5,6}$, Carmen Ferrara7, \\ Caterina Lonati ${ }^{8^{*}}$ (D) and Giorgio Walter Canonica ${ }^{9}$
}

\begin{abstract}
Background: Despite availability of clinical guidelines, underdiagnosis, undertreatment, and poor adherence are still significant concerns in allergic rhinitis (AR) therapeutic management. We investigated clinical practice patterns and prescribing behavior of Italian healthcare professionals (HCPs) specialized in AR.

Methods: One-hundred allergologists, 100 ear, nose and throat (ENT) specialists, and 150 general practitioners (GPs) were recruited. The survey assessed: socio-demographic, work experience, monthly caseload, prescription drivers. Next, HCPs were invited to retrospectively recover patients' clinical data to investigate: AR clinical characteristics, therapy management, prescription patterns, patient adherence. Descriptive statistics, Chi square, One-Way analysis of variance, and Two-Way Analysis of Variance were performed.

Results: Allergologists visited more AR patients (31\% of monthly caseload) than ENTs ( $21 \%, p<0.001$ ), while GPs' caseload was the lowest (6\%). Clinical information of 2823 patients were retrieved of whom 1906 (67.5\%) suffered from moderate/severe AR (discomfort score: $7.7 \pm 1.3$ ) and 917 (32.4\%) from mild AR (5.7 \pm 1.9 ). About one-third of mild patients had a discomfort score $\geq 7$. Main prescription drivers were "effective on all symptoms" (54.3\% patients) and "quick symptom relief" (47.8\%), whereas minor drivers were "affordable price" (13.4\%) and "refundable" (8.7\%). The most prescribed drugs were antihistamines and intranasal corticosteroids ( $79 \%$ and $55 \%$ prescriptions), followed by fixed-dose-combination of intranasal azelastine/fluticasone (19\%). Polytherapy was the most common treatment strategy (59.6\%). HCPs' believe that the majority of the patients was adherent to treatment ( $88 \%$ with score > 7).
\end{abstract}

Conclusions: This survey describes the therapeutic approach adopted by Italian physicians to cope with AR and shows that HCPs underestimated AR severity and had a non-realistic perception of patients' adherence. These findings suggest that further efforts are required to improve AR clinical management in Italy.

Keywords: Allergic rhinitis, Italy, Allergologists, General practitioners, ENT specialists, Pharmacological management, Undertreatment, Patient adherence

*Correspondence: caterina.Ionati@policlinico.mi.it; caterina.lonati@gmail.com ${ }^{8}$ Center for Preclinical Research, Fondazione IRCCS Ca' Granda Ospedale Maggiore Policlinico, via Pace 9, 20122 Milan, Italy

Full list of author information is available at the end of the article

\section{Introduction}

Allergic rhinitis (AR) is one of the most common disease affecting adults worldwide with increasing incidence and prevalence in almost all western countries [1-5]. Though it is not a serious condition, AR is widely accepted as a clinically relevant and disabling disorder accounting for a substantial burden of global morbidity $[3,6]$ and it is associated with considerable economic impact [7-9]. 
Indeed, patients with AR experience particularly bothersome symptoms which negatively affects their everyday activities and quality of sleep, ultimately leading to reduced quality of life (QoL) [3, 10-12] and impaired work and school performance $[9,13]$. In asthmatics subjects, coexistent AR exacerbates severity of asthma [14, 15].

Despite international and national are continuously reviewed and updated to optimize patient care guidelines (e.g. Allergic Rhinitis and its Impact on Asthma, ARIA) [16-19], AR clinical management is still unsatisfactory, with high rates of underdiagnosis $[12,20,21]$ and undertreatment [20-23]. Inadequate control of symptoms not only is associated with delayed medical examinations and patient preference for over-the-counter drugs, but it can also cause serious diseases such as nasal polyp development, acute and chronic sinusitis, and otitis media [23, 24]. Patients' low adherence to therapy is an additional factor affecting achievement of proper symptom control [25-27].

In Italy, prevalence of AR has increased over the last 20 years from 16.8 to $25.8 \%$ [1,28, 29]. A survey by Spinozzi and coworkers showed that over half of the patients recruited by general practitioners (GPs) experience symptoms which significantly impairs their daily/social life [30]. Strikingly, more than $25 \%$ of the interviewed subjects received no treatment despite the symptoms and $13.5 \%$ were inadequately treated. In addition, recent studies reported poor adherence to ARIA guidelines by Italian clinicians $[31,32]$.

The present research investigated the current clinical practice patterns and prescribing behaviour of Italian healthcare professionals (HCPs) specialized in AR management. Allergologists, ear, nose and throat (ENT) specialists, and GPs were asked to retrospectively recover clinical data of real-life cases to assess: (1) prescribing behaviour based on patients' characteristics; (2) AR therapeutic management; (3) opinions toward patients' adherence.

\section{Methods}

\section{Design, HCPs' recruitment, and data collection}

We carried out a survey among a total of 350 Italian HCPs treating patients suffering from AR. The survey sample included 100 allergologists, 100 ENT specialists, and 150 GPs. HCPs were randomly selected from a national database. Exclusion criteria were: $<5$ years of clinical practice, $<5$ AR patients visited over the last month, participation to another market research in the previous 6 months. Recruitment was carried out via mail and it was planned to equally represent physicians from all Italian geographical macro-regions in each specialty area. The interviews were performed in April 2019 and data were collected through Computer Assisted Web Interviewing (CAWI) lasting 20 min.

The questionnaire used in the present research was designed based on findings from a systematic literature review and included two sections. The first section collected the HCPs' socio-demographic data, such as age, gender, years of work experience, and number of monthly visited patients with AR. HCPs' attitude toward relevant prescription drivers was likewise investigated (Additional file 1: Appendix S1).

In the second section of the survey, HCPs were invited to retrospectively recover clinical information of the patients they visited over the last month. The information retrieved included patients' demographics, disease characteristics (disease symptoms, presence of concomitant asthma) and symptoms-related discomfort experienced by patients and disease severity (Additional file 1: Appendix S2). More specifically, HCPs were asked to allocate their patients into 2 classes of severity: (1) mild, when symptoms experienced by patients do not interrupt sleep or interfere with daytime activities; (2) moderate/severe, when symptoms cause significant difficulties with sleep and adversely affect daytime function [33]. Thereafter, therapy management, i.e. class of prescribed drugs, medication regimen, and follow-up intervals were investigated (Additional file 1: Appendix S3). Medication regimes included: (1) monotherapy, when a single drug was used; (2) concomitant polytherapy, in which different drugs were simultaneously used; (3) sequential polytherapy, in which the use of a specific drug was sequential to the use of another drug (i.e. drugs given one after the other); (4) polytherapy, in which different drugs were used, some to be taken continuously and other to be taken as-needed. Next, prescription drivers based on patients' characteristics (Additional file 1: Appendix S4) were assessed. Physicians' opinions about patient adherence to treatment was likewise explored (Additional file 1: Appendix S5). Finally, HCPs' perception of AR economic burden (i.e. patients' absenteeism from work and reduced productivity) was evaluated (Additional file 1: Appendix S6).

\section{Statistical analysis}

Data were homogenously collected by means of a questionnaire including both multiple choice questions and Likert scale-based questions. A descriptive analysis was performed for all the evaluated variables, presenting the absolute frequencies in case of categorical variables and the mean with standard deviation in the case of the continuous variables. Mean ratings obtained from Likerttype scale-framed questions were used to investigate differences across study groups.

Differences in variable distributions across specialists were tested with $\mathrm{X}_{2}$ Chi square/or One Way analysis of 
variance (ANOVA) when appropriate. Kruskal-Wallis One Way Analysis of Variance on Ranks followed by Dunn's post hoc test were likewise used. Two Way ANOVA was used to investigate significance between specialty area and patient assignment to the different classes of AR severity. Tukey's post hoc test was used for pairwise multicomparison procedure.

A $p<0.05$ was considered statistically significant. The data were analyzed using the statistics software SigmaPlot 11.0 (Systat Software, San Jose, CA, USA).

\section{Results}

\section{Physicians' sample characteristics and prescription drivers}

Relevant characteristics of the 350 respondents are described in Table 1. With regard to AR caseload, allergologists visited more patients in the last month (a median of 40 patients, $31 \%$ of total caseload) than ENTs (21 patients, $21 \%)(\mathrm{p}<0.001)$, while GPs' caseload was the lowest (18 patients, $6 \%$ of caseload). About half of the patients seen by allergologists (45\%) and ENTs (42\%) received a new diagnosis of AR, whereas $80 \%$ of the AR patients visited by GPs were already diagnosed $(\mathrm{p}<0.001)$.
All the prescription drivers presented through the questionnaire (Additional file 1: Appendix S1) were rated high by the interviewed clinicians (average scores were $>7$ ). Drivers with the highest score were "effective on all AR symptoms" (average score of the whole sample: $9.1 \pm 1.1)$ and "few/no side effects" $(9.1 \pm 1.0)$. On the other hand, cost-related aspects were associated with the lowest scores in all the specialty groups and with smaller percentage of physicians endorsing the positive response options (i.e. score $>9$ ). For instance, only $36 \%$ of allergologists, $17 \%$ of ENTs, and $29 \%$ of GPs gave a positive answer to the item "refundable".

\section{Patients' sample characteristics}

Clinical information of 2823 patients suffering from AR were collected; 909 patient records were retrieved by allergologists, 606 by ENTs, and 1308 by GPs (Table 2). Considering the whole sample, mean age of the majority of patients was $<44$ (1902 patients, 67\%) and 1414 patients $(50.1 \%)$ were men. Analysis of patient clinical data confirmed that allergologists (327 patients, 36\%) and ENTs (206 patients, 34\%) visited more patients needing a new diagnosis than GPs (277 patients, 21\%).

Table 1 HCPs' characteristics

\begin{tabular}{|c|c|c|c|c|c|}
\hline Characteristic & $\begin{array}{l}\text { Whole sample } \\
\mathrm{N}=350\end{array}$ & $\begin{array}{l}\text { Allergologists } \\
\mathrm{N}=100\end{array}$ & $\begin{array}{l}\text { ENTs } \\
N=100\end{array}$ & $\begin{array}{l}\text { GPs } \\
N=150\end{array}$ & p value \\
\hline Age, years & $56.9 \pm 8.2$ & $53.47 \pm 10.91$ & $55.60 \pm 7.80$ & $60.28 \pm 5.40$ & $<0.001$ \\
\hline Clinical experience, years & $27.7 \pm 9.4$ & $24.48 \pm 11.10$ & $27.28 \pm 8.65$ & $30.14 \pm 7.92$ & $<0.001$ \\
\hline Geographic area & & & & & - \\
\hline Northwest Italy & $86(24.5 \%)$ & $25(7.1 \%)$ & $24(6.8 \%)$ & $37(10.5 \%)$ & \\
\hline Northeast Italy & $60(17.1 \%)$ & $14(4 \%)$ & $19(5.4 \%)$ & $27(7.7 \%)$ & \\
\hline Central & $78(22.2 \%)$ & $25(7.1 \%)$ & $21(6 \%)$ & $32(9.1 \%)$ & \\
\hline South and Insular Italy & $126(36 \%)$ & $36(10.2 \%)$ & $36(10.2 \%)$ & $54(15.4 \%)$ & \\
\hline Patients volume/month & $210[100-400]$ & 150 [100-247] & $150[100-300]$ & $400[300-500]$ & $<0.001$ \\
\hline AR patients volume/month & $20[12-50]$ & $40[20-80]$ & $21[14-50]$ & $18[10-30]$ & $<0.001$ \\
\hline$\%$ of new diagnosis/month & $33.4 \pm 25.3$ & $45.3 \pm 24.7$ & $42.1 \pm 25.4$ & $19.6 \pm 18.0$ & $<0.001$ \\
\hline \multicolumn{6}{|l|}{ Prescription drivers } \\
\hline Quick symptom relief & $8.9 \pm 1.2$ & $9.0 \pm 1.2$ & $8.9 \pm 1.3$ & $8.8 \pm 1.3$ & 0.490 \\
\hline Effective with few drugs & $8.8 \pm 1.3$ & $9.9 \pm 1.0$ & $8.7 \pm 1.5$ & $8.7 \pm 1.4$ & 0.219 \\
\hline Effective on all AR symptoms & $9.1 \pm 1.1$ & $9.4 \pm 0.9$ & $9.1 \pm 1.1$ & $9.1 \pm 1.3$ & 0.101 \\
\hline Sustained efficacy & $8.9 \pm 1.1$ & $8.9 \pm 1.1$ & $9.0 \pm 1.2$ & $8.9 \pm 1.3$ & 0.819 \\
\hline Few/no side effects & $9.1 \pm 1.0$ & $9.3 \pm 1.1$ & $9.2 \pm 1.1$ & $9.1 \pm 1.0$ & 0.373 \\
\hline Supported by scientific literature & $8.6 \pm 1.4$ & $8.9 \pm 1.5$ & $8.7 \pm 1.3$ & $8.5 \pm 1.4^{*}$ & 0.043 \\
\hline Easy to take & $8.5 \pm 1.4$ & $8.7 \pm 1.3$ & $8.4 \pm 1.9$ & $8.6 \pm 1.3$ & 0.434 \\
\hline Increased patient adherence & $8.8 \pm 1.2$ & $8.9 \pm 1.2$ & $8.9 \pm 1.4$ & $8.8 \pm 1.1$ & 0.794 \\
\hline Refundable & $6.8 \pm 2.5$ & $7.5 \pm 2.6$ & $5.7 \pm 2.9^{*} \#$ & $7.2 \pm 2.1$ & $<0.001$ \\
\hline Affordable price & $8.1 \pm 1.7$ & $8.4 \pm 1.6$ & $7.9 \pm 0.2$ & $8.2 \pm 0.1$ & 0.128 \\
\hline
\end{tabular}

Data are expressed as mean \pm SD, median [25-75] or $\mathrm{N}(\%)$. Chi squared test was used to investigate differences in the observed frequencies across specialty area. In case of discrete variables, differences across specialty area were evaluated using one way analysis of variance followed by Tukey test for all pairwise multiple comparison procedure or Kruskal-Wallis one way analysis of variance on ranks followed by Dunn's post hoc test: $p<0.05:{ }^{*}$ vs allergologists, \# vs GPs 
Table 2 Patients' characteristics

\begin{tabular}{|c|c|c|c|c|c|}
\hline Characteristic & $\begin{array}{l}\text { Whole sample } \\
\mathrm{N}=2823\end{array}$ & $\begin{array}{l}\text { Allergologists } \\
\mathrm{N}=909\end{array}$ & $\begin{array}{l}\text { ENTs } \\
N=606\end{array}$ & $\begin{array}{l}\text { GPs } \\
N=1308\end{array}$ & $p$-value \\
\hline Age, years & & & & & $<0.001$ \\
\hline $18-24$ & $630(22.3 \%)$ & $249(27.3 \%)$ & $148(24.4 \%)$ & $233(17.8 \%)$ & \\
\hline $25-34$ & $622(22 \%)$ & $219(24 \%)$ & $134(22.1 \%)$ & $269(20.5 \%)$ & \\
\hline $35-44$ & $650(23 \%)$ & $197(21.6 \%)$ & $139(22.9 \%)$ & $314(24 \%)$ & \\
\hline $45-54$ & $503(17.8 \%)$ & $149(16.3 \%)$ & 99 (16.3\%) & $255(19.4 \%)$ & \\
\hline$>55$ & $412(15 \%)$ & $91(10 \%)$ & 85 (14\%) & $236(18 \%)$ & \\
\hline Disease duration, years & $10[5-19]$ & $10[4-15]$ & $10[5-20]^{*}$ & $10[5-20]^{*}$ & $<0.001$ \\
\hline New diagnosis & $810(29 \%)$ & $327(36 \%)$ & $206(34 \%)$ & $277(21 \%)$ & $<0.001$ \\
\hline AR causes & & & & & 0.635 \\
\hline Graminaceous pollens & $1450(51.3 \%)$ & $414(45.5 \%)$ & $314(51.8 \%)$ & $722(55.1 \%)$ & \\
\hline Tree pollens & $873(30.9 \%)$ & $249(27.3 \%)$ & $165(27.2 \%)$ & 459 (35\%) & \\
\hline Grass pollens & $722(25.5 \%)$ & $250(27.5 \%)$ & $168(27.7 \%)$ & $304(23.2 \%)$ & \\
\hline Dust/dust mites & $1150(40.7 \%)$ & $352(38.7 \%)$ & $304(50.1 \%)$ & $494(37.7 \%)$ & \\
\hline Animal allergens & $459(16.2 \%)$ & $130(14.3 \%)$ & $111(18.3 \%)$ & $218(16.6 \%)$ & \\
\hline Mould & $262(9.2 \%)$ & $64(7 \%)$ & 69 (11.3\%) & $129(9.8 \%)$ & \\
\hline Cockroaches & $14(0.4 \%)$ & $5(0.5 \%)$ & $2(0.3 \%)$ & $7(0.5 \%)$ & \\
\hline Other & $5(0.1 \%)$ & $2(0.2 \%)$ & $0(0 \%)$ & $3(0.2 \%)$ & \\
\hline Concomitant asthma treatment & $605(89.8 \%)$ & $238(88.5 \%)$ & $95(88 \%)$ & $272(91.3 \%)$ & 0.242 \\
\hline
\end{tabular}

Patients' data were retrospectively retrieved by the interviewed HCPs. Data are expressed as number of patients (\%) ore median [25-75]. Chi squared test was used to investigate differences in the observed frequencies across specialty area. Kruskal-Wallis One Way Analysis of Variance on Ranks, All Pairwise Multiple Comparison Procedures (Dunn's method): $p<0.05:{ }^{*}$ vs allergologists

Pollens were the more frequent cause of AR, followed by dust mites. More specifically, 1313 patients (46.5\%) were allergic only to pollens, 439 (15.6\%) only to dust, $222(7.9 \%)$ to other causes, 849 (30.1\%) to more than one cause. About a quarter of the cases (674 patients, $23.9 \%$ ) suffered from concomitant asthma and the majority of these patients $(605,89.9 \%)$ took a specific drug for asthma treatment. Among asthmatic patients, 213 were only allergic to pollens, 117 only to dust, 36 only to other causes.

\section{AR clinical characteristics and disease severity according to HCPs}

As shown in Table 3, symptoms reported by patients were similar across specialists. The most common symptoms involved upper respiratory tract: 2148 patients (76\%) experienced congestion, 1931 (68.4\%) sneezing, 1712 (60.6\%) itchy nose, and 1677 (59.4\%) runny nose. Ocular symptoms were likewise very common: itchy eyes affected 1085 patients (38.4\%), red eyes 990 (35\%), and watery eyes 983 (34.8\%).

From a physicians' perspective, distribution of AR severity in the patients' sample was: 1906 (67.5\%) patients with moderate/severe AR and 917 (32.4\%) patients with mild AR (Table 3). Concerning symptoms-related discomfort, physicians rated with high scores $(>7)$ the majority of their patients (1982 patients, 70.2\%). Average scores of symptoms-related discomfort according to AR severity were $7.7 \pm 1.3$ for the moderate/severe group and $5.7 \pm 1.9$ for the mild group. Notably, about half of the patients assigned to the mild category were reported to suffer from extremely bothersome symptoms (Fig. 1a). ENTs rated these patients with higher scores relative to both allergologists and GPs $(6.5 \pm 1.3$ vs $5.4 \pm 1.9$ and $5.6 \pm 2.1$, respectively, $\mathrm{p}<0.001$ ) (Fig. $1 \mathrm{~b}$ ).

Investigation of AR impact on patients' professional life disclosed that about one-third of patients (1042 patients, 37.0\%) reported reduced productivity due to AR (1338 patients with moderate/severe AR and 72 patients with mild, Additional file 1: Appendix S7, panel A). The majority of cases (703 patients, $67.7 \%$ ) had a productivity impact score $>7$. According to physicians, 551 patients (19.7\%) complaints of work absenteeism due to AR, of whom 404 suffered from moderate/severe AR and 15 from mild AR (Additional file 1: Appendix S7, panel B).

\section{HCPs' prescribing behaviour and AR therapy management}

Table 4 reports the main prescription drivers based on patients' characteristics. Overall, data were consistent with the previous analysis shown in Table 1 . In fact, the item "effective on all AR symptoms" was the main prescription driver for the majority of patients (1533 patients on average, $54.3 \%$ ), followed by "quick symptom relief" (1352 patients, $47.8 \%$ ). On the other hand, "affordable 
Table 3 Clinical characteristics of patients suffering from AR

\begin{tabular}{|c|c|c|c|c|c|}
\hline Item & $\begin{array}{l}\text { Whole sample } \\
\mathrm{N}=2823\end{array}$ & $\begin{array}{l}\text { Allergologists } \\
\mathrm{N}=909\end{array}$ & $\begin{array}{l}\text { ENTs } \\
N=606\end{array}$ & $\begin{array}{l}\text { GPs } \\
N=1308\end{array}$ & p-value \\
\hline AR symptoms & & & & & $<0.001$ \\
\hline Congestion & $2148(76 \%)$ & $686(75.4 \%)$ & $513(84.6 \%)$ & 949 (72.5\%) & \\
\hline Sneezing & $1931(68.4 \%)$ & $669(73.5 \%)$ & $379(62.5 \%)$ & $883(67.5 \%)$ & \\
\hline Itchy nose & $1712(60.6 \%)$ & $617(67.8 \%)$ & $305(50.3 \%)$ & $790(60.3 \%)$ & \\
\hline Runny nose & $1677(59.4 \%)$ & $609(66.9 \%)$ & $369(60.8 \%)$ & $699(53.4 \%)$ & \\
\hline Itchy eyes & $1085(38.4 \%)$ & $366(40.2 \%)$ & $131(21.6 \%)$ & $588(44.9 \%)$ & \\
\hline Red eyes & $990(35 \%)$ & $303(33.3 \%)$ & $123(20.2 \%)$ & $564(43.1 \%)$ & \\
\hline Watery eyes & $983(34.8 \%)$ & 307 (33.7\%) & $151(24.9 \%)$ & $525(40.1 \%)$ & \\
\hline Cough & $651(23 \%)$ & $214(23.5 \%)$ & $104(17.1 \%)$ & $333(25.4 \%)$ & \\
\hline Itchy palate & $461(16.3 \%)$ & $184(20.2 \%)$ & $100(16.5 \%)$ & $177(13.5 \%)$ & \\
\hline Difficult breathing & $388(13.7 \%)$ & $127(13.9 \%)$ & $91(15 \%)$ & $170(12.9 \%)$ & \\
\hline Wheezing & $369(13 \%)$ & $144(15.8 \%)$ & $35(5.7 \%)$ & $190(14.5 \%)$ & \\
\hline Sleep disorders/insomnia & $193(6.8 \%)$ & $48(5.2 \%)$ & $46(7.5 \%)$ & $99(7.5 \%)$ & \\
\hline Irritability & $143(5 \%)$ & $30(3.3 \%)$ & $22(3.6 \%)$ & $91(6.9 \%)$ & \\
\hline Chest tightness & $117(4.1 \%)$ & $51(5.6 \%)$ & $7(1.1 \%)$ & $59(4.5 \%)$ & \\
\hline Fatigue & $116(4.1 \%)$ & $32(3.5 \%)$ & $18(2.9 \%)$ & $66(5 \%)$ & \\
\hline Eczema & $95(3.3 \%)$ & $29(3.1 \%)$ & $16(2.6 \%)$ & $50(3.8 \%)$ & \\
\hline AR severity & & & & & $<0.001$ \\
\hline Moderate/severe & $1906(67.5 \%)$ & $626(68.8 \%)$ & $456(75.3 \%)$ & $824(62.3 \%)$ & \\
\hline Mild & $917(32.4 \%)$ & $283(31.1 \%)$ & $150(24.7 \%)$ & $484(37 \%)$ & \\
\hline Symptoms-related discomfort & & & & & $<0.001$ \\
\hline Extremely bothersome (10-7) & $1982(70.2 \%)$ & $604(66.4 \%)$ & $484(79.9 \%)$ & $894(68.3)$ & \\
\hline Moderately bothersome (6-5) & $540(19.1 \%)$ & $188(20.7 \%)$ & $106(17.5 \%)$ & $246(18.8 \%)$ & \\
\hline Not bothersome (4-1) & $301(10.7 \%)$ & $117(12.9 \%)$ & $16(2.6 \%)$ & $168(12.8 \%)$ & \\
\hline Discomfort scores according to severity & & & & & $<0.001$ \\
\hline Moderate/severe & $7.7 \pm 1.3$ & $7.7 \pm 1.4$ & $7.8 \pm 1.2$ & $7.7 \pm 1.5$ & 0.368 \\
\hline Mild & $5.7 \pm 1.9$ & $5.4 \pm 1.9$ & $6.5 \pm 1.3^{*} \#$ & $5.6 \pm 2.1$ & $<0.001$ \\
\hline
\end{tabular}

Patients' clinical information was retrospectively retrieved by the interviewed HCPs. Data are expressed as mean \pm SD or number of patients (\%). Chi squared test was used to investigate differences in the observed frequencies across specialty area. One-way analysis of variance or two-way analysis of variance (factor A: specialty area, factor B: AR severity) followed by Tukey's post hoc test. $\mathrm{p}<0.001$ : ${ }^{*}$ vs allergologists, \# vs GPs

price" and "refundable" were ranked low and were considered as relevant prescription drivers only for $13.4 \%$ and $8.7 \%$ of patients, respectively. Of note, "increased patient adherence" was the main prescription drivers for about $40 \%$ of patients visited by ENTs and GPs (40\% and $35 \%$ of patients, respectively), while it was considered less significant by allergologists (28\% of patients).

Polytherapy was the most common treatment strategy adopted by the interviewed physicians (1653 patients, $59.6 \%$ ), while monotherapy was used in $41.4 \%$ of cases (1170 patients) (Table 4). Allergologists more often recommended polytherapy (606 patients, 66.7\%, p <0.001), while GPs adopted a monotherapy-based therapeutic approach for about half of their cases (621 patients, 47.4\%, $\mathrm{p}<0.001)$.

With regard to prescribed medications, the most recommended classes of drugs were antihistamines and intranasal corticosteroids (2246 and 1549 prescriptions, respectively) followed by fixed-dose combination of intranasal azelastine/fluticasone (Aze/flu) (543 prescriptions) (Fig. 2). Compared to allergologists and ENTs, GPs less often recommended corticosteroids and fixed-dose combination of Aze/flu ( $p<0.001$, Fig. 2).

Figure 3a shows the use of the different classes of drugs in either monotherapy or polytherapy regimens. Drugs preferentially used in monotherapy varied significantly across clinicians. Antihistamines were the most recommended medications by allergologists and GPs (50\% of patients and $77 \%$ of patients, respectively), whereas ENTs more often prescribed corticosteroids (42\%) and fixeddose combination of Aze/flu (41\%). Concerning polytherapy, loose combinations of antihistamines and intranasal corticosteroids were the most prescribed drugs (57\%, $59 \%$, and $64 \%$ of patients by allergologists, ENTs, and GPs, respectively). Aze/flu was largely used in monotherapy by ENTs (41\%), while allergologists and GPs 


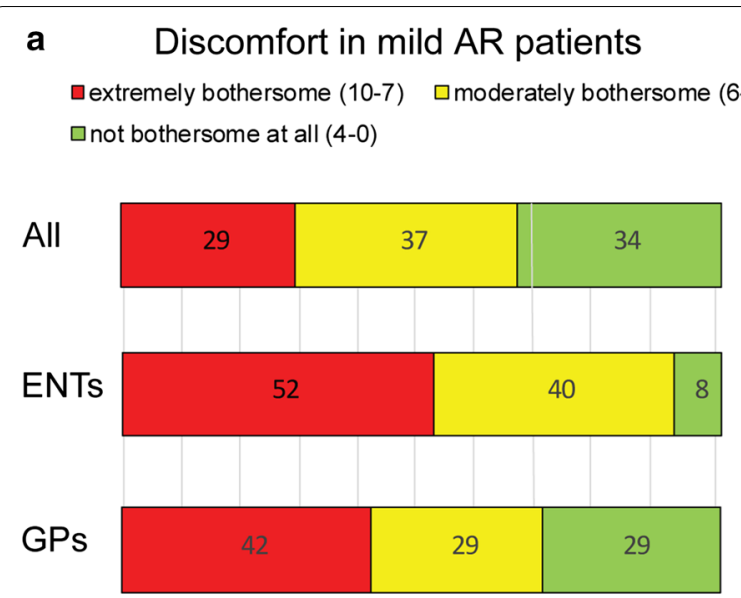

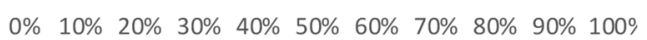

b

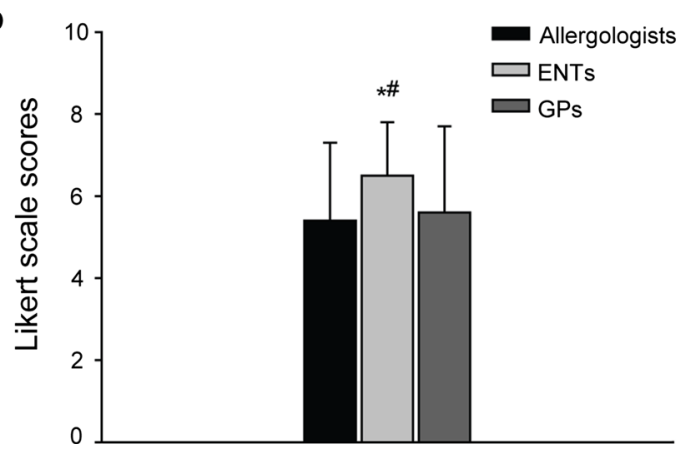

Fig. 1 Symptoms-related discomfort experienced by patients suffering from mild AR. a Level of discomfort experienced by mild patients according to physicians. 10-point Likert scale: $1-4=$ Not bothersome at all; $5-6=$ moderately bothersome; $7-10=$ Extremely bothersome. $\mathbf{b}$ Average scores of symptom discomfort. One way analysis of variance; all pairwise multiple comparison procedure (Tukey Test): $p<0.05$ : Asterisk vs allergologists, \# vs GPs

preferentially prescribed this drug in combination with antihistamines by (36\% and 27\%, respectively). Figure $3 \mathrm{~b}$ displays the main prescription drivers adopted by HCPs in monotherapy and polytherapy regimes considering the most prescribed drugs, i.e. antihistamines, corticosteroids, and Aze/Flu.

In a further analysis focused on AR therapy management based on patients' severity, treatment regimen and main prescription drivers were independently investigated for mild and moderate/severe patients (Additional file 1: Appendix S8). All the interviewed clinicians adopted different therapeutic approaches for mild and moderate/severe AR.

\section{HCPs' opinions about patient adherence to treatment}

Physicians believe that the majority of the patients ( $88 \%$ of patients with score $>7$ ) has good adherence to treatment, even in the cases of severe AR (Fig. 4a). In HCPs' opinion the main reasons for low patient compliance were "relief from the symptoms" and "treatment cost" (Fig. 4b).

\section{Discussion}

The present survey investigated the current clinical practice scenario of AR management in Italy. In addition to provide an extensive description of Italian HCPs' prescribing behaviour, this study discloses clinicians' perspective about patients' symptom discomfort and adherence.

AR is characterized by substantial medical and social burden with high use of healthcare resources worldwide $[5,6,11,34]$. In addition, this disorder is associated with absenteeism from work, reduced productivity, and poor school performance [34, 35]. Recent studies indicate not only a global increase in the AR prevalence $[3,6,36]$, but also high rates of underdiagnosis [3] and inadequate treatment [22].

In our survey, allergologist emerged as the main reference specialist for the disease in Italy, followed by ENTs. GPs visited more cases suffering from mild AR compared to both allergologists and ENTs. Prescription attitude was similar between HCPs. Attributes related to medication efficacy, safety, and patient adherence were considered more relevant prescription drivers than ease of use and cost-related items.

Consistent with previous Italian studies [31, 32], the most prescribed drugs were antihistamines and intranasal corticosteroids. A novel data disclosed by our survey is that allergologists and ENTs recommended fixed-dose combination intranasal Aze/flu to about $20 \%$ of the patients they visited. It is well-established that intranasal corticosteroids provide a more effective control of symptoms than antihistamines but their effect is relatively slow (hours) [18]. Fixed-dose combination of intranasal fluticasone propionate and azelastine hydrochloride was shown to be more efficacious than intranasal corticosteroid monotherapy [37-42] and it offers the additional benefit of faster relief of symptoms (minutes) [39, 40, 43]. This drug is also indicated when monotherapy with either intranasal antihistamines or corticosteroids do not adequately control the symptoms of AR [39, 41, 42, 44]. Of note, randomized clinical trials showed that fixed-dose formulation is more effective than loose combinations of corticosteroids and antihistamines in patients with moderate/severe seasonal AR [44]. The newest ARIA guidelines based on both Grading of Recommendations Assessment, Development and Evaluation (GRADE) and real-world evidence (RWE) confirm and emphasize efficacy of fixed-dose combination of intranasal Aze/flu for both nasal and ocular symptom relief and recommend the use of this drug as first line therapy for AR patients 
Table 4 AR therapeutic management by the interviewed physicians

\begin{tabular}{|c|c|c|c|c|c|}
\hline Item & $\begin{array}{l}\text { Whole sample } \\
\mathrm{N}=2823\end{array}$ & $\begin{array}{l}\text { Allergologists } \\
\mathrm{N}=909\end{array}$ & $\begin{array}{l}\text { ENTs } \\
N=606\end{array}$ & $\begin{array}{l}\text { GPs } \\
N=1308\end{array}$ & p-value \\
\hline Main prescription drivers & & & & & $<0.001$ \\
\hline Effective on all AR symptoms & $1533(54.3 \%)$ & $501(55.1 \%)$ & $335(55.2 \%)$ & $697(53.2 \%)$ & \\
\hline Quick symptom relief & $1352(47.8 \%)$ & $429(47.1 \%)$ & $287(47.3 \%)$ & $636(48.6 \%)$ & \\
\hline Increased patient adherence & $959(33.9 \%)$ & 255 (28\%) & $242(39.9 \%)$ & $462(35.3 \%)$ & \\
\hline Sustained efficacy & $921(32.6 \%)$ & 307 (33.7\%) & $189(31.1 \%)$ & $425(32.4 \%)$ & \\
\hline Few/no side effects & $911(32.2 \%)$ & $303(33.3 \%)$ & $164(27 \%)$ & $444(33.9 \%)$ & \\
\hline Effective with few drugs & $849(30 \%)$ & $290(31.9 \%)$ & $198(32.6 \%)$ & $361(27.5 \%)$ & \\
\hline Easy to take & $848(30 \%)$ & $228(25 \%)$ & $192(31.6 \%)$ & $428(32.7 \%)$ & \\
\hline Supported by scientific literature & $470(16.6 \%)$ & $216(23.7 \%)$ & $127(20.9 \%)$ & $127(9.7 \%)$ & \\
\hline Affordable price & $379(13.4 \%)$ & $137(15 \%)$ & $70(11.5 \%)$ & $172(13.1 \%)$ & \\
\hline Refundable & $246(8.7 \%)$ & $60(6.6 \%)$ & $14(2.3 \%)$ & $172(13.1 \%)$ & \\
\hline Follow-up timing & & & & & $<0.001$ \\
\hline$<12$ months & $86(3 \%)$ & $36(4 \%)$ & $24(4 \%)$ & $26(2 \%)$ & \\
\hline Every 12 months & $1166(41 \%)$ & $427(47 \%)$ & $242(40 \%)$ & $497(38 \%)$ & \\
\hline Every 6 months & $722(26 \%)$ & $272(30 \%)$ & $188(31 \%)$ & $262(20 \%)$ & \\
\hline$<6$ months & $865(31 \%)$ & $172(19 \%)$ & $157(26 \%)$ & $536(41 \%)$ & \\
\hline Treatment regimen & & & & & $<0.001$ \\
\hline Monotherapy & $1170(41.4 \%)$ & $303(33.3 \%)$ & 246 (40.5\%) & $621(47.4 \%)$ & \\
\hline Polytherapy & $1653(59.6 \%)$ & $606(66.7 \%)$ & $360(59.4 \%)$ & $687(52.5 \%)$ & \\
\hline
\end{tabular}

Data are expressed as number of patients (\%). Chi squared test was used to investigate differences in the observed frequencies across specialty area

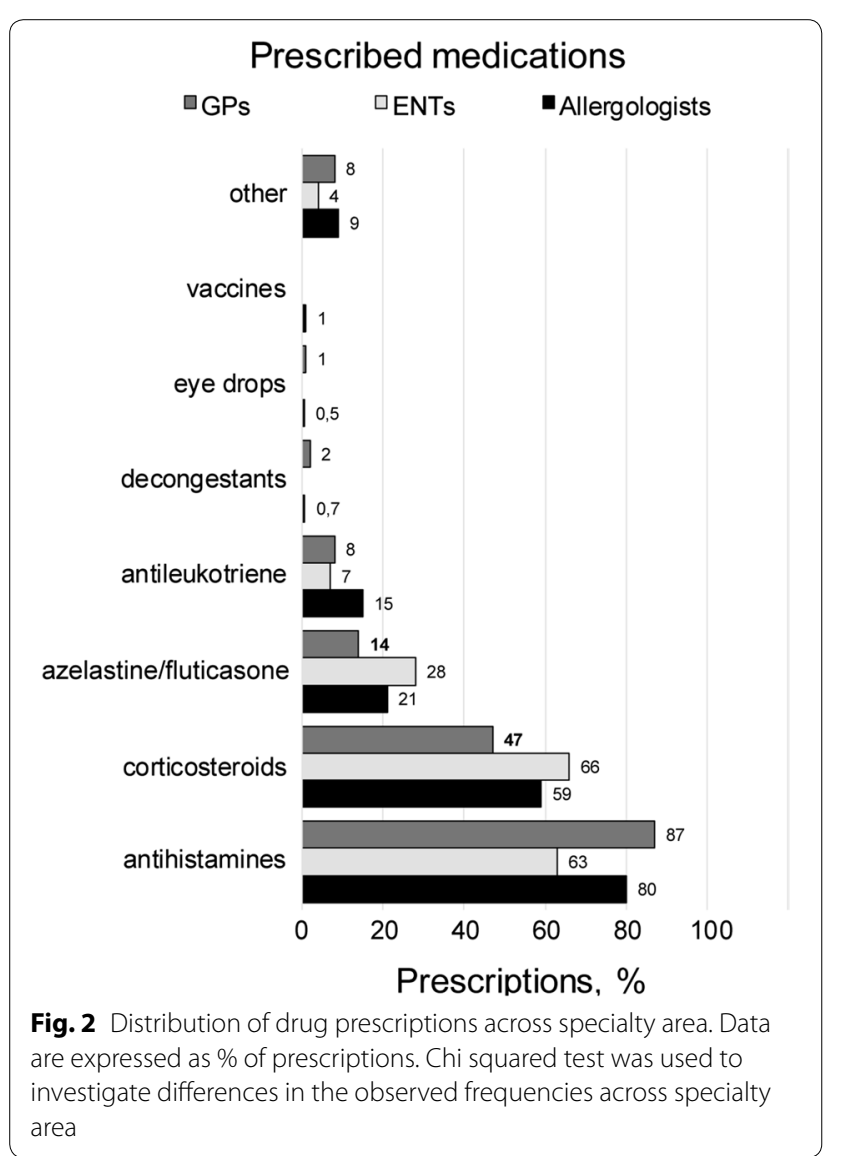

[45]. Our analysis showed that fixed-dose combination intranasal Aze/flu was used in both monotherapy and polytherapy regimens, with significant differences across clinicians. In fact, Aze/flu was preferentially used in monotherapy by ENTs, whereas it was more frequently recommended in polytherapy regimens by allergologists and GPs. This latter therapeutic strategy involved the simultaneous use of Aze/flu mainly together with antihistamines (ebastine, desloratine, bilastine). Assessing the risk of therapeutic duplication in patients suffering from AR is a crucial question that requires specific investigation.

A remarkable finding of the present survey is that AR severity is underestimated by physicians, irrespective of the specialty area in which they operate. In fact, about half of the patients assigned to the mild class of severity actually experienced particularly bothersome symptoms. This observation is consistent with data reported by the European survey carried out in Germany, France, Italy, Spain, and UK, in which clinicians not only underestimated the severity of disease but also misdiagnosed the nature and discomfort of symptoms [12]. As a correct classification of symptom frequency and severity is essential to select the best treatment option for each patient $[13,18,46]$, an inaccurate patients' allocation to severity categories can significantly affect AR therapeutic management. The results provided by our analysis of AR pharmacological management according to 
a

In monotherapy

$\square$ aze/flu $\square$ antihistamines $\square$ corticosteroids

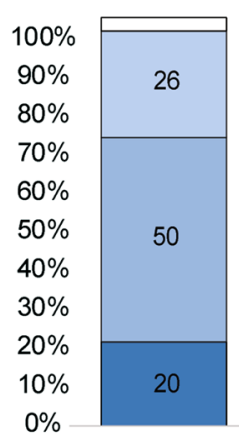

All

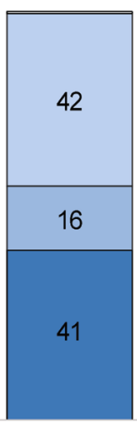

ENTs

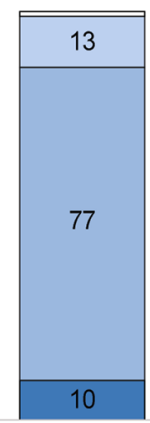

GPs
Drug prescriptions

\section{In polytherapy}

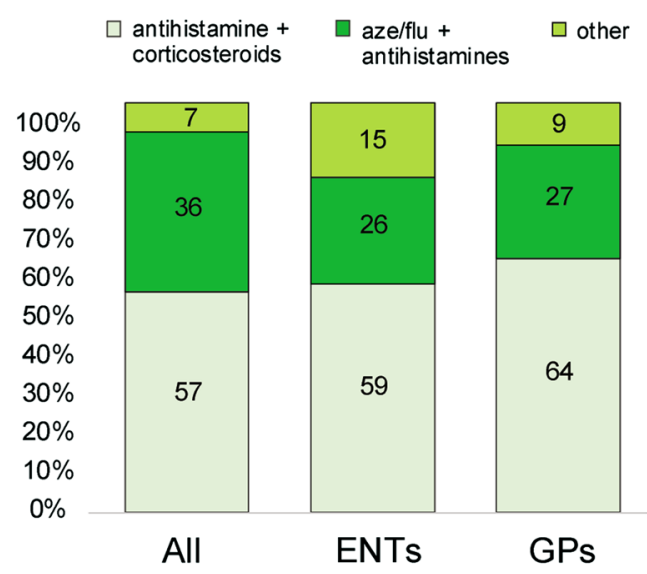

b

Main prescription drivers

\section{In monotherapy}

$\square$ aze/flu $\square$ corticosteroids $\square$ antihistamines
In polytherapy

$\square$ aze/flu $\square$ corticosteroids $\square$ antihistamines

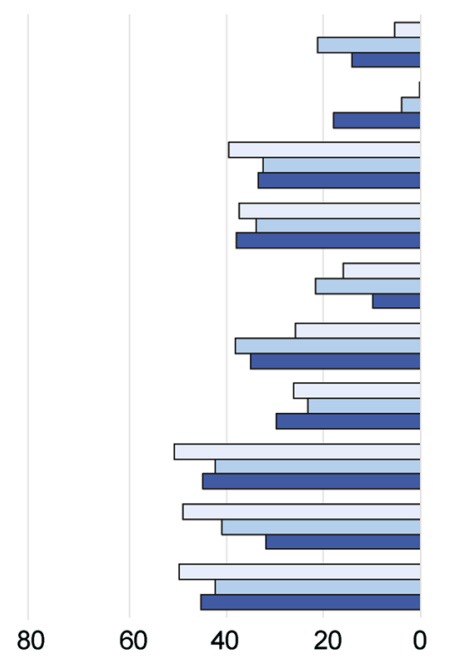

affordable price
refundable
increased patient
adherence
easy to take
supported by
scientific literature
few/no side effects
sustained efficacy
effective on all
AR symptoms
effective with few drugs
quick symptom relief
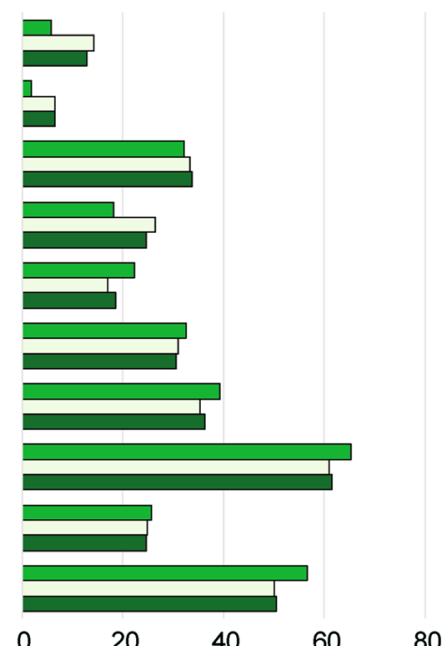

Patients, \%

Fig. 3 Monotherapy and polytherapy regimes: classes of drugs and main prescription drivers. a Use of the different classes of drugs within either monotherapy or polytherapy regimens. Monotherapy involves the use of a single drug, while polytherapy regimens are based on the use of different drugs. Data are expressed as \% of patients. Chi squared test was used to investigate differences in the observed frequencies across specialty area. b Main prescription drivers in monotherapy and polytherapy regimes. Data are expressed as \% of patients. Chi squared test was used to investigate differences in the frequencies across the different drugs. Aze/flu fixed-dose combination azelastine/fluticasone

patients' severity further supports this concept. Indeed, patients assigned to moderate/severe AR were preferentially recommended a polytherapy-based approach rather than a monotherapy regimen. Based on this, we can speculate that some of the patients improperly assigned to the mild category were undertreated. AR undertreatment and inadequate management have been extensively documented [20-22], suggesting that this disease is still trivialized in some cases [3, 22, 23]. 


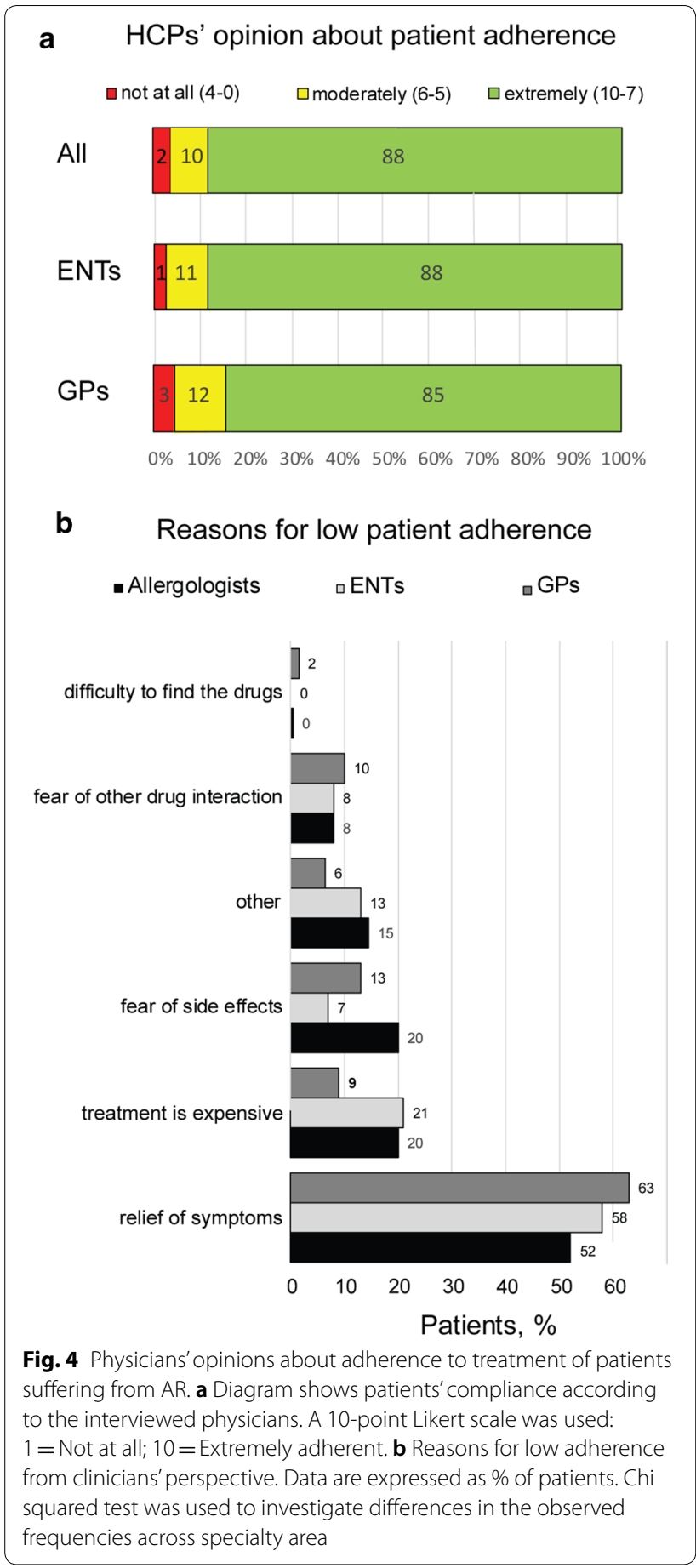

With regard to HCPs' opinions about patient adherence, our investigation disclosed that clinicians believe all the patients are compliant, even in the cases of severe AR. This perception does not reflect the real scenario of patients' adherence in the AR settings. In fact, it is widely accepted that adherence in AR patients is very low $[25,26,47,48]$. A recent study, in which compliance was assessed in a real-life setting using a mobile phone App, confirmed that about $70 \%$ of the recruited European AR patients are non-adherent to medications [26]. HCPs' misperception of patient adherence in our sample could be partly due to low frequency of follow-up visits (once a year) and to a poor patients-clinicians communication [12, 49].

According to the interviewed physicians, the main cause of low compliance was relief of AR symptoms, followed by cost-related issues. Lack of efficacy, adverse effects, treatment duration, and costs are generally associated with lower compliance [50]. Patient satisfaction with treatment likewise appears to be a relevant factor in determining compliance, even if its contribution still needs to be elucidated. In fact, many researchers reported that dissatisfaction with treatment may cause non-adherence to therapy [51-53], whereas more recent studies revealed that patients discontinue their treatment when they felt better $[47,54]$. In contrast to guidelines recommending the use of multiple drugs to achieve symptom control [45], recent data indicated that most patients experience poor symptom control with increasing medications [26, 55]. Hence, the use of single drug-based therapy could substantially ameliorate patient compliance. Finally, concerning drug cost, it is widely accepted that affordability of prescription medication has a role in therapy persistence [25]. Of interest, clinicians recruited in our survey did not consider cost issues as relevant prescription drivers.

\section{Conclusions}

AR still represents a significant health problem because of the high burden of symptoms and the significant impact on patients' QoL. The various available clinical guidelines state that accurate diagnosis, thorough patient evaluation, and adequate follow-up monitoring are a prerequisite to ensure optimal patient care.

The present research showed severity of AR symptoms is underestimated by Italian physicians, regardless of the specialty area in which they operate. This could lead to inadequate control of the disease. In addition, HCPs are not fully aware of the poor adherence to treatment.

These findings suggest that further efforts should be made to promote physicians' adherence to clinical guidelines in order to improve AR management in Italy. Design of educational interventions for both GPs and specialists could improve characterization of the disease, help clinicians in the selection of the best treatment option, and promote a better patient-physician communication on the nature, severity, and impact of symptoms. 


\section{Supplementary information}

Supplementary information accompanies this paper at https://doi. org/10.1186/s12948-020-00135-4.

Additional file 1. Supplementary methods and results.

\section{Abbreviations}

AR: Allergic rhinitis; ARIA: Allergic Rhinitis and its Impact on Asthma; Aze/flu: Azelastine/fluticasone; ENT: Ear, nose and throat; GPs: General practitioners; GRADE: Grading of Recommendations Assessment, Development and Evaluation; HCPs: Healthcare professionals; QoL: Quality of life; RWE: Real-world evidence.

\section{Acknowledgements}

The authors thank Doxa Pharma S.r.l. for data collection and analysis.

\section{Author contribution}

GP, AM, GS, JB, CF, and GWC designed the survey and interpreted the data; $\mathrm{CL}$ analyzed the data and wrote the manuscript. Authors agreed both to be personally accountable for the author's own contributions and to ensure that questions related to the accuracy or integrity of any part of the work, even ones in which the author was not personally involved, are appropriately investigated, resolved, and the resolution documented in the literature. All authors read and approved the final manuscript.

\section{Funding}

The survey was funded by Mylan N.V.

\section{Availability of data and materials}

The findings of the survey are available from Doxa Pharma S.r.l. However, these data were used under license and consequently they are not publicly available. Data are available from the authors upon reasonable request and with permission of Doxa Pharma S.r.l.

\section{Ethics approval and consent to participate}

The present survey did not require ethics committees' approval as no health intervention had been administered to participants (Italian law Decreto 8 febbraio 2013 n. 34).The research was conducted by Doxa Pharma S.r.l. in compliance with the General Data Protection Regulation (EU) 2016/679 (GDPR) and in line with well-established regulatory practices/procedures governing marketing research, including the Market Research Society (MRS) code of conduct (2019 revision) and the Italian Code of Professional Ethics (ASSIRM, 2016 revision).Physicians actively chose to participate to the survey and signed the following documents: data retention policy, data privacy statement, and data processing agreement. The interview questions were not aimed at investigating sensitive issues like religious or political beliefs or sexual orientation. Doxa Pharma S.r.l ensured pseudonymization of individual answers before primary data abstraction and analysis.

\section{Consent for publication}

All the authors gave consent to publication of the manuscript and, in case of its acceptance, the copyright is transferred to Clinical and Molecular Allergy.

\section{Competing interests}

The authors declare that they have no competing interests.

\section{Author details}

${ }^{1}$ Allergy and Respiratory Diseases, IRCCS Policlinico San Martino, University of Genoa, Genoa, Italy. ${ }^{2}$ Allergy Unit, National Healthcare System, Scilla, Reggio Calabria, Italy. ${ }^{3}$ Unità Operativa di Allergologia-Asma Center-Azienda Ospedaliera, Universitaria Integrata di Verona, Verona, Italy. ${ }^{4}$ Comprehensive Allergy Center, Department of Dermatology and Allergy, Charité-Universitätsmedizin Berlin, Corporate Member of Freie Universität Berlin, HumboldtUniversität zu Berlin, and Berlin Institute of Health, Berlin, Germany. ${ }^{5}$ Centre Hospitalier Universitaire de Montpellier, Montpellier, France. ${ }^{6}$ MACVIA-France, Montpellier, France. ${ }^{7}$ Mylan Italy s.r.l, Milan, Italy. ${ }^{8}$ Center for Preclinical Research, Fondazione IRCCS Ca' Granda Ospedale Maggiore Policlinico, via
Pace 9, 20122 Milan, Italy. ${ }^{9}$ Asthma \& Allergy Clinic-Humanitas University \& Research Hospital Milan, Milan, Italy.

Received: 11 August 2020 Accepted: 16 September 2020

Published online: 03 November 2020

\section{References}

1. De Marco R, Cappa V, Accordini S, Rava M, Antonicelli L, Bortolami O, et al. Trends in the prevalence of asthma and allergic rhinitis in Italy between 1991 and 2010. Eur Respir J. 2012;39(4):883-92.

2. Bjerg A, Ekerljung L, Middelveld R, Dahlén SE, Forsberg B, Franklin K, et al. Increased prevalence of symptoms of rhinitis but not of asthma between 1990 and 2008 in Swedish adults: comparisons of the ECRHS and GA2LEN surveys. PLOS ONE. 2011. https://doi.org/10.1371/journal.pone.0016082.

3. Bauchau V, Durham SR. Prevalence and rate of diagnosis of allergic rhinitis in Europe. Eur Respir J. 2004:24(5):758-64.

4. Nathan RA, Meltzer EO, Selner JC, Storms W. Prevalence of allergic rhinitis in the United States. J Allergy Clin Immunol. 1997;99:808-14.

5. Schatz M. A survey of the burden of allergic rhinitis in the USA. Allergy Eur J Allergy Clin Immunol. 2007;62(SUPPL. 85):9-16.

6. Nathan RA. The burden of allergic rhinitis. Allergy Asthma Proc. 2007:28(1):3-9.

7. Zuberbier T, Lötvall J, Simoens S, Subramanian SV, Church MK. Economic burden of inadequate management of allergic diseases in the European Union: a GA 2 LEN review. Allergy Eur J Allergy Clin Immunol. 2014;69(10):1275-9.

8. Reed SD, Lee TA, McCrory DC. The economic burden of allergic rhinitis: a critical evaluation of the literature. PharmacoEcon. 2004;22(6):345-61.

9. Stróżek J, Samoliński BK, Kłak A, Gawińska-Drużba E, Izdebski R, KrzychFałta E, et al. The indirect costs of allergic diseases. Int J Occup Med Environ Health. 2019;32(3):281-90.

10. Bousquet J, Khaltaev N, Cruz AA, Denburg J, Fokkens WJ, Togias A, et al. Review article allergic rhinitis and its impact on asthma (ARIA) 2008 Review Group. Prim Care. 2008;63:8-160.

11. Valero A, Alonso J, Antépara I, Baró E, Colás C, Del Cuvillo A, et al. Health-related quality of life in allergic rhinitis: comparing the short form ESPRINT-15 and MiniRQLQ questionnaires. Allergy Eur J Allergy Clin Immunol. 2007;62(12):1372-8.

12. Canonica JB, Mullol GKS, Virchow JC. A survey of the burden of allergic rhinitis in Europe. Allergy. 2007;62(85):17-25.

13. Seidman MD, Gurgel RK, Lin SY, Schwartz SR, Baroody FM, Bonner JR, et al. Allergic rhinitis (Summary). Otolaryngol. 2014. https://doi. org/10.1177/0194599814562166.

14. Maio S, Baldacci S, Simoni M, Angino A, Martini F, Cerrai S, et al. Impact of asthma and comorbid allergic rhinitis on quality of life and control in patients of italian general practitioners. J Asthma. 2012;49(8):854-61.

15. Valovirta E, Pawankar R. Survey on the impact of comorbid allergic rhinitis in patients with asthma. BMC Pulmon Med. 2006:6:3.

16. Hellings PW, Seys SF, Marien G, Agache I, Canonica W, Gevaert P, et al. ARIA masterclass 2018: from guidelines to real-life implementation. Rhinology. 2019:57(5):392-9.

17. Bousquet J, Bedbrook A, Czarlewski W, Onorato GL, Arnavielhe S, Laune D et al. Guidance to 2018 good practice: ARIA digitally-enabled, integrated, person-centred care for rhinitis and asthma. Clin Transl Allergy. 2019;9:16.

18. Brożek JL, Bousquet J, Agache I, Agarwal A, Bachert C, Bosnic-Anticevich $\mathrm{S}$, et al. Allergic rhinitis and its impact on asthma (ARIA) guidelines-2016 revision. J Allergy Clin Immunol. 2017;140(4):950-8.

19. http://www.progetto-aria.it/aim.htm.

20. Esteban CA, Klein RB, Kopel SJ, McQuaid EL, Fritz GK, Seifer R, et al. Underdiagnosed and undertreated allergic rhinitis in urban school-aged children with asthma. Pediatr Allergy Immunol Pulmonol. 2014;27(2):75-81.

21. Nolte H, Nepper-Christensen S, Backer V. Unawareness and undertreatment of asthma and allergic rhinitis in a general population. Respir Med. 2006;100(2):354-62.

22. Maurer M, Zuberbier T. Undertreatment of rhinitis symptoms in Europe: findings from a cross-sectional questionnaire survey. Allergy Eur J Allergy Clin Immunol. 2007;62(9):1057-63. 
23. Zuberbier T, Lötvall J, Simoens S, Subramanian SV, Church MK. Economic burden of inadequate management of allergic diseases in the European Union: a GA 2 LEN review. Allergy. 2014;69(10):1275-9.

24. Demoly P, Calderon MA, Casale T, Scadding G, Annesi-Maesano I, Braun Ju, et al. Assessment of disease control in allergic rhinitis. Clin Transl Allergy. 2013;3(1):1-7

25. Baena-Cagnani CE, Canonica GW, Zaky Helal M, Gómez RM, Compalati $E$, Zernotti ME, et al. The international survey on the management of allergic rhinitis by physicians and patients (ISMAR). World Allergy Organ J. 2015;8(1):1-11.

26. Menditto E, Costa E, Midão L, Bosnic-Anticevich S, Novellino E, Bialek S, et al. Adherence to treatment in allergic rhinitis using mobile technology. The MASK Study. Clin Exp Allergy. 2018;2019:442-60.

27. Bousquet J, Hellings PW, Agache I, Amat F, Annesi-Maesano I, Ansotegui IJ, et al. Allergic Rhinitis and its Impact on Asthma (ARIA) Phase 4 (2018): change management in allergic rhinitis and asthma multimorbidity using mobile technology. J Allergy Clin Immunol. 2019;143(3):864-79.

28. Verlato G, Corsico A, Villani S, Cerveri I, Migliore E, Accordini S, et al. Is the prevalence of adult asthma and allergic rhinitis still increasing? Results of an Italian study. J Allergy Clin Immunol. 2003;111(6):1232-8.

29. Serra G. Burden of allergic rhinitis in Italy : findings of the ARTE study. Allergic Rhinitis. 2002;8:43-53.

30. Spinozzi F, Murgia N, Baldacci S, Maio S, Pala AP, Casciari C, et al. Characteristics and predictors of allergic rhinitis undertreatment in primary care Int J Immunopathol Pharmacol. 2016;29(1):129-36.

31. Canonica GW, Triggiani M, Senna GE. 360 degree perspective on allergic rhinitis management in Italy: a survey of GPs, pharmacists and patients. Clin Mol Allergy. 2015;13(1):1-8.

32. Maio S, Simoni M, Baldacci S, Angino A, Martini F, Cerrai S, et al. The ARGA study with Italian general practitioners: prescriptions for allergic rhinitis and adherence to ARIA guidelines. Curr Med Res Opin. 2012;28(10):1743-51.

33. Lee $\mathrm{CH}$, Jang JH, Lee HJ, Kim I-T, Chu MJ, Kim CD, et al. Clinical characteristics of allergic rhinitis according to allergic rhinitis and its impact on asthma guidelines. Clin Exp Otorhinolaryngol. 2008;1(4):196.

34. Ozdoganoglu T, Songu M. The burden of allergic rhinitis and asthma. Ther Adv Respir Dis. 2012;6(1):11-23.

35. Marshall JB. Allergic diseases as a public health problem in Europe. Eur Allergy White Pap. 1997;22:689-97

36. Asher M, Montefort S, Bjorksten B, Lai C, Strachan D, Weiland S, et al. Worldwide time trends in the prevalence of symptoms of asthma, allergic rhinoconjunctivitis, and eczema in childhood. Lancet. 2006;368(9537):733-43.

37. Dykewicz MS, Wallace DV, Baroody F, Bernstein J, Craig T, Finegold I, et al. Treatment of seasonal allergic rhinitis an evidence-based focused 2017 guideline update. Ann Allergy Asthma Immunol. 2017. https://doi. org/10.1016/j.anai.2017.08.012.

38. Meltzer E, Ratner P, Bachert C, Carr W, Berger W, Canonica GW, et al. Clinically relevant effect of a new intranasal therapy (MP29-02) in allergic rhinitis assessed by responder analysis. Int Arch Allergy Immunol. 2013;161(4):369-77.

39. Emeryk A, Emeryk-Maksymiuk J, Janeczek K. New guidelines for the treatment of seasonal allergic rhinitis. Postep Dermatol Alergol. 2019;36(3):255-60.

40. Bousquet J, Schünemann HJ, Hellings PW, Arnavielhe S, Bachert C, Bedbrook A, et al. MACVIA clinical decision algorithm in adolescents and adults with allergic rhinitis. J Allergy Clin Immunol. 2016;138(2):367-374 e2.
41. Carr W Bernstein J, Lieberman P Meltzer E, Bachert C Price D et al. A novel intranasal therapy of azelastine with fluticasone for the treatment of allergic rhinitis. J Allergy Clin Immunol. 2012;129(5):1282-9.

42. Ratner P, Hampel F, Wheeler W, Sacks H. Efficacy of azelastine hydrochloride and fluticasone propionate combined in a single delivery device for treatment of ocular symptoms of seasonal allergic rhinitis. In: Ann Allergy, Asthma Immunol 2009 Annu Sci Meet Am Coll Allergy, Asthma Immunol ACAAI Miami, FL United StatesConference Start 20091105 Conf End 20091110 Conference Publ. 2009.

43. Bousquet J, Meltzer EO, Couroux P, Koltun A, Kopietz F, Munzel U, et al. Onset of action of the fixed combination intranasal azelastine-fluticasone propionate in an allergen exposure chamber. J Allergy Clin Immunol Pract. 2018;6(5):1726-32.

44. Hampel FC, Ratner PH, Van Bavel J, Amar NJ, Daftary P, Wheeler W, et al. Double-blind, placebo-controlled study of azelastine and fluticasone in a single nasal spray delivery device. Ann Allergy Asthma Immunol. 2010;105:168-73.

45. Bousquet J, Schünemann HJ, Togias A, Bachert C, Erhola M, Hellings PW et al. Next-generation allergic rhinitis and its impact on asthma (ARIA) guidelines for allergic rhinitis based on grading of recommendations assessment, development and evaluation (GRADE) and real-world evidence. J Allergy Clin Immunol. 2019;145(1):70-80.

46. Braido F, Arcadipane F, Marugo F, Hayashi M, Pawankar R. Allergic rhinitis: current options and future perspectives. Curr Opin Allergy Clin Immunol. 2014;14(2):168-76.

47. Bender BG. Motivating patient adherence to allergic rhinitis treatments. Curr Allergy Asthma Reports. 2015;15:10.

48. Valovirta EDR. Patient adherence to allergic rhinitis treatment: results from patient surveys. Medscape J Med. 2008;38:19-42.

49. Harrison E. The cost of not taking our medicine: the complex causes and effects of low medication adherence. Am J Accountable Care. 2018;6(4):11-3.

50. Köberlein J, Kothe AC, Schaffert C. Determinants of patient compliance in allergic rhinoconjunctivitis. Curr Opin Allergy Clin Immunol. 2011;11(3):192-9.

51. Baiardini I, Braido F, Bonini M, Compalati E, Canonica GW. Why do doctors and patients not follow guidelines? Curr Opinion Allergy Clin Immunol. 2009:9(3):228-33

52. Marple BF, Fornadley JA, Patel AA, Fineman SM, Fromer L, Krouse JH, et al. Keys to successful management of patients with allergic rhinitis: Focus on patient confidence, compliance, and satisfaction. Otolaryngol. 2007:136(6):S107-24.

53. Ciprandi G, Incorvaia C, Scurati S, Puccinelli P, Soffia S, Frati F, et al. Patient-related factors in rhinitis and asthma: the satisfaction with allergy treatment survey. Curr Med Res Opin. 2011;27(5):1005-11.

54. Huang X, Matricardi PM. Allergy and asthma care in the mobile phone era. Clin Rev Allergy Immunol. 2019;56(2):161-73.

55. Bédard A, Basagaña X, Anto JM, Garcia-Aymerich J, Devillier P, Arnavielhe S, Bedbrook A, Onorato GL, Czarlewski W, Murray R, Almeida R, Fonseca J, Costa E, Malva J, Morais-Almeida M, Pereira AM, Todo-Bom A, Menditto E, Stellato C. Mobile technology offers novel insights into the control and treatment of allergic rhinitis: The MASK study. J Allergy Clin Immunol. 2019:144(1):135-43.

\section{Publisher's Note}

Springer Nature remains neutral with regard to jurisdictional claims in published maps and institutional affiliations. 